\title{
The comparative impact of lexical translation and lexical inferencing on EFL learners' vocabulary retention
}

\author{
Nasim Shangarfam $^{a}$, Neda Ghorbani ${ }^{b^{*}}$, Ehsan Safarpoor $^{\mathrm{b}}$, and Mahshid Maha ${ }^{\mathrm{c}}$
}

${ }^{a}$ Associate Professor, Department of English, Central Tehran branch, Islamic Azad University, Tehran, Iran

${ }^{b}$ Department of English, Central Tehran branch, Islamic Azad University, Tehran, Iran

${ }^{c} M A$ student in ELT course of Aras International University, Tabriz. Iran

\section{H R O N I C L E}

Article history:

Received August 16, 2013

Received in revised format

12 September 2013

Accepted 1 November 2013

Available online

November 72013

Keywords:

Vocabulary retention

Lexical translation

Lexical inferencing

English as Foreign Language

(EFL) learners

\section{A B S T R A C T}

\begin{abstract}
The present study is an attempt to investigate the comparative effects of lexical translation and lexical inferencing techniques on Female intermediate EFL learners' vocabulary retention. For this purpose, 90 female learners attending the Jahad Daneshgahi Center in Qom took a piloted sample KET test, 60 of whom were selected as homogenous learners. They were randomly divided into two experimental groups-one learning new vocabulary items through lexical translation technique and the other with the lexical inferencing technique. They were given a pre-test on vocabulary to ensure that the participants had no prior knowledge of the target words. Then all participants in both groups were taught using the same material and received the same amount of instruction. The only difference was for teaching of new lexical items. One experimental group was taught mainly through the lexical translation technique while the other experimental group learned by the lexical inferencing technique. After conducting the treatment, a post-test was administered to both groups in order to measure the students' ability in the retention of the lexical items taught through lexical translation and lexical inferencing techniques after a two-week interval. The analysis of the test scores using independent sample t-test revealed that the lexical inferencing group significantly outperformed the lexical translation group on the retention of the lexical items suggesting its benefits for teaching new words. Findings provide insights to teachers as well as students on how to best approach learning new lexical items.
\end{abstract}

\section{Introduction}

In recent years second language vocabulary acquisition has become an increasingly interesting topic of discussion for researchers, teachers, curriculum designers, theorists, and others involved in second language learning, and a number of influential books focusing on vocabulary were published (Bogaards \& Laufer, 2004; Coady \& Huckin, 1997; Folse, 2004; Nation, 1990, 2001; Schmitt, 2000; Schmitt \& McCarthy, 1997). At the same time, research articles focusing on vocabulary issues

* Corresponding author.

E-mail addresses: safarpoorehsan@yahoo.com (N. Ghorbani) 
appeared with regularity. Nunan (1991) considered knowing adequate vocabulary as the most important factor in communication and believed that one might not be able to use the structures learned for comprehensible communication without having a good command of vocabulary.

In fact focusing on vocabulary is so important that Coady and Huckin (1997) considered lexical competence as the centre of communicative competence. Moreover, Weigand (1998) claimed that "to learn a language means to know how words are used and what utterances are used in specific situations" (p.44). Several approaches to language learning including the lexical syllabus (Willis, 1990), lexical phrases and language teaching (Nattinger \& DeCarrico, 1992), and the lexical approach (Lewis, 1993) have been proposed that view vocabulary and lexical units as central in language learning and teaching (Richards \& Rodgers, 2001, p.132). Lexical approaches in language teaching seek to develop proposals for syllabus design and language teaching founded on a view of language in which lexis plays the central role.

Not only researchers but also language teachers have paid special attention to vocabulary. Candlin (1988, cited in Knight, 1994) pointed out "the study of vocabulary is at the heart of language teaching in terms of the organization of syllabuses, the evaluation of learners' performance, and the provision of learning resources". Fowle (2002) believed that vocabulary learning should be central to the language program, and language teachers should help students develop the necessary skills for processing and learning new lexical items. He goes on to suggest that Learning vocabulary causes major problems for a foreign language student, and it is probably the most difficult aspect of foreign language instruction because of the inherent complexities of the task and the great differences in the attitudes of learners.

Teachers usually use different methods to teach vocabulary in classrooms. For example, Carter (2001) believed that teachers could help learners in vocabulary learning explicitly by means of paired translation equivalents, word lists and in variously related semantic sets. They can also help learners by more indirect or implicit means, such as exposing learners to words in the context of reading real texts. Nation (2001) believed in a systematic approach to vocabulary instruction. He stated that one should focus on vocabulary as a part of the design of communicative task and argued that vocabulary teaching should be integrated into listening, speaking, reading, and writing, i.e. vocabulary can be acquired by receiving meaning-focused input through reading and listening, through meaningfocused-output by speaking and writing, through fluency development and through language-focused instruction.

Now that vocabulary is a current focus in ESL pedagogy and research (Wei, 2007), a fundamental query is why learning vocabulary is such a challenging and unproductive experience. Which method could be used to make vocabulary less of a struggle? Generally speaking, vocabulary can be taught in different ways each of which with its own merits and demerits. Lexical inferencing, as one of these ways, has been defined as the connections that people establish when they try to interpret texts. EFL learners can possibly derive the meaning of unknown words using the context in which they appear, that is, a sentence in which the word to be learned appears. Training learners to employ strategies has been proven as being of paramount importance in helping learners to make use of inferencing in context (Prince, 1996). Lexical-inferencing allows the learners to learn vocabulary without the help of the teacher and they can continue their reading without stopping to check words in the dictionary.

Lexical inferencing, "involves making informed guesses as to the meaning of a word in light of all available linguistic cues in combination with the learner's general knowledge of the world, his/her awareness of context and his/her relevant linguistic knowledge" (Haastrup, 1987, p. 197). Lexical inferencing can be applied for purposes of immediate comprehension in a reading, speaking, or even listening context, and it may lead to retention of the word form as well as semantic and other lexical information (Paribakht \& Wesche, 1999). 
On the other hand, lexical translation is frequently used by teachers in foreign language pedagogy since it seems to be the first, easiest and readily available method of instruction. This involves the simple provision of an equivalent for the lexical items in the target language. However, Prince (1996) states that simply knowing translations for L2 words does not "guarantee that they will be successfully accessed for use in an L2 context" (p. 488). As is evident from the literature discussed above, a state of indeterminacy exists as to the learners' ability to transfer the lexical knowledge which is mainly acquired through learning via translation. Kaivanpanah and Alavi (2008) found that learners cannot rely on their own guesses about the meanings of words in the context. The context and contextual clues have been considered as a significant factor in inferencting new vocabularies. Hence, many studies have discussed about their effect.

Vasiljevic, (2008) examined the effectiveness of 3 different approaches to vocabulary instruction in an advanced reading class: word associations, explicit definitions and inferring word meaning from context. A small-scale experiment focused on advanced adult Japanese learners of English who have limited contact with the target language. The three approaches were evaluated based on their contribution to the growth of both receptive and productive word knowledge. It was concluded that instruction through word associations seemed to offer some potential advantages over other forms of explicit instruction. It strengthened the links between the items in L2 mental lexicon, and helped build new concepts for L2 learners, consequently resulting in a greater degree of automaticity and accuracy in production. Another advantage of the word association approach was that it minimized learners' reliance on the L1. Unlike, an Explicit Definition approach where learners acquired the basic meaning of the word, instruction through simple word associations went beyond the simple meaning definitions. It helps learners build links between the words that belong to the same semantic field and acquire knowledge of collocations specific to L2.

Webb, (2008) investigated the effects of context on Japanese university students learning English as a foreign language. One group of learners met the target words in contexts rated more highly than the contexts read by the other group. The results showed that the group that read the contexts containing more contextual clues had significantly higher scores on both tests of meaning. The findings indicated that the quality of the context rather than the number of encounters with target words might have a greater effect on gaining knowledge of meaning. Conversely, it is the number of encounters that will have a greater effect on knowledge of form.

Zaid (2009) used two approaches to vocabulary instruction to 34 learners of Level Three in College of Languages and Translation. One strategy was applied for direct teaching of the individual meanings for a set of unfamiliar words. Students should derive word meaning from sentence context, rather than teaching specific meanings. Findings indicated that both approaches were effective in helping students acquire, retain and further recall the lexical items instructed.

Keyvanfar, and Arya, (2009) tried to address impact of directive contexts and general context on vocabulary retention of Iranian EFL learners. The control group received the target words' definitions out of context, while the first experimental group encountered the target words in "directive contexts" and the other experimental group in "general contexts". Results indicated that there was no significant difference among the 3 groups in their "productive" vocabulary knowledge whereas the "directive context" group outperformed the "general context" group by their "receptive vocabulary" knowledge. They concluded that the directive contexts rich in contextual clues have a significant impact on the students' receptive knowledge.

Zafarani (2009) investigated the effects of different cognitive learning strategies on the immediate and long-term receptive retention of EFL vocabulary. Results indicated that context-based inferential strategy users made more gains both on the immediate and the delayed recall tests. This supports the superiority of guessing over key word and consultation strategies. 
Istifici (2009) investigated the type of inferencing strategies used on intermediate and lowerintermediate students. When all the inferences are taken into account, it can be said that the students at intermediate level were more successful than the students at low-intermediate level in their guesses of the meaning of unknown words. It was found that students at low-intermediate level concentrated more on the words when they read a passage due to the number of unknown words in the reading passages. It was observed that when they encountered an unknown, they stopped reading the rest of the passage and tried to find the meaning of the word. But the students at intermediate level tried to understand the whole passage by looking at the context and getting the general idea of passage; they did not spend most of their time on trying to guess the meaning of unknown words. It can be said that students at the 2 levels use a wide variety of inferencing strategies. However, students at intermediate level had had more correct inferences than low-intermediate level.

Pellicer-Sanchez and Schmitt (2010) investigated the degree to which relatively advanced L2 readers could acquire spelling, word class, and recognition and recall of meaning from reading the unmodified authentic novel "Things Fall Apart" on 20 Spanish learners of English. Their results showed that some learning occurred with few repetitions. After more than 10 exposures, the meaning and spelling could be recognized for $84 \%$ and $76 \%$ of the words respectively, while the meaning word class could be recalled for $55 \%$ and $63 \%$.

Yali (2010) explored the role of reading in L2 vocabulary acquisition, and the effect of instructional techniques (incidental and intentional) on the vocabulary learning of ESL students of different levels in Chinese universities. Following findings were yielded: 1) both instructional treatments resulted in significant gains in learner's receptive vocabulary knowledge, but the combination of the incidental and intentional learning instruction leads to greater vocabulary gains and better retention. 2). Students' vocabulary size plays a decisive role in acquiring the productive aspect of the vocabulary knowledge.

Shokouhi and Askari (2010) studied the impact of a contextual guessing strategy on vocabulary and reading authentic texts at the pre-university. One-hundred male and female students were randomly selected and assigned to context and non-context groups. The context group received a contextual guessing strategy to infer the meaning of low-frequency words while the non-context participants were treated by a direct method. The results revealed that contextual guessing strategy instruction was more effective than direct vocabulary instruction and was more effective than the non-context method in improving reading. Thus, the results suggest that a more effective way to produce large-scale vocabulary growth is through contextual guessing strategy.

The best monolingual teacher and the ideal narrator being at one and the same time a native speaker of L2, while the best way to acquire the language was to replicate the language learning process of a child in its acquisition of a first language (Cook 2010). In response to criticism directed at the grammar-translation method in terms of text and material selection, the communicative approach postulated the use of non-contrived texts and examples, together with learning situations which imitate real life. Lexical translation is frequently used by teachers in foreign language pedagogy since it seems to be the first, easiest and readily available method of instruction. This involves the simple provision of an equivalent for the lexical items in the target language. However, scholars like Prince (1996) states that simply knowing translations for L2 words does not "guarantee that they will be successfully accessed for use in an L2 context" (p. 488). As is evident from the literature discussed above, a state of indeterminacy exists as to the learners' ability to transfer the lexical knowledge which is mainly acquired through learning via translation.

Present study is an attempt to make a comparison between the two techniques discussed (lexical inferencing and lexical translation) to see whether or not they can make any difference in student's vocabulary development process. 


\section{Statement of the Problem}

Regarding the importance of learning vocabulary in EFL contexts and the need felt for an appropriate technique of teaching lexical items, many studies have been conducted to find alternative teaching techniques with more capacity to impart meaningful learning in the context of teaching English. In spite of the significance of inferencing in learning and the crucial role it plays in meaningful learning, there are not many studies in the literature aimed at capturing something of students' knowledge structure. Hence, there appears to be the potential for teaching lexical inferencing strategies in EFL context for developing students' lexical repertoire.

\subsection{Significance of the Study}

The present study is considered to be significant for some reasons. It can offer pedagogical applications for teachers, students as well as text book developers. First of all, the results can help teachers have a better view on using the lexical inferencing technique in teaching new words. Secondly, the results can help students have a better view on using vocabulary learning techniques rather than avoiding them. Finally, textbook developers can also take substantial benefits from this study. They can incorporate these techniques for learning new words in the syllabus of the course books.

\subsection{Research Question and Null Hypothesis}

Is there any significant difference between the effect of lexical translation and lexical inferencing techniques on EFL learners' vocabulary retention?

$\mathrm{H}_{0}$ 1. There is no significant difference between the effect of lexical translation and lexical inferencing techniques on EFL learners' vocabulary retention.

\subsection{Limitations and delimitation of the Study}

The researcher studied the effect of sentential context on learning and retention of lexical items due to time limitation in language schools. Thus, further research may take place to study the effect of longer context on learning and retention of words. Also the participants of the study were all female students since the researcher, being a female herself did not have access to male student classes. In fact, the researcher could choose only female participants due to the regulations of the Ministry of Education in Iran and the female teachers are not allowed to teach male students. The study was also developed under a delimitation applied by the researcher herself. Participation in this study was delimited to intermediate students of Jahad Daneshgahi center in Qom who were able to score one standard deviation above and below the mean in a standard test of language proficiency. This was due to the lack of enough linguistic knowledge by elementary students which made them inappropriate candidates for applying the lexical inferencing technique in dealing with new lexical items. In fact inferencing may be difficult for most beginners. Advanced students, on the other hand, were thought to be already familiar with the techniques of lexical inferencing and in fact most of the time they attempt to infer the meaning of new words rather than relying on finding the Persian equivalents. Therefore the researcher in the present study decided to focus on the intermediate students who were considered to be the best possible sample.

\section{Methodology}

\subsection{Participants}

The participants of this study were 60 Iranian EFL learners who studied English in the Jahad Daneshgahi Center in Qom. They were females whose age ranged from 18 to 30 with the average age of 24. Their language proficiency was intermediate level according to the criteria set by the language school and their educational levels varied from high school diploma to bachelor's degrees as well as master's degrees in different fields. The participants were selected from among 90 students via the 
administration of a KET (Key English Test). In addition, 30 participants with similar characteristics to that of the target sample took part in the piloting of the present study's instruments.

\subsection{Instrument}

In order to come up with a homogeneous sample, a proficiency test was administered in this study. To minimize the individual differences among the participants and to ensure the close homogeneity of them, a version of the KET (Key English Test) proficiency test was employed as a reliable and standard criterion to help the researcher choose a sample.

The second instrument was a researcher made vocabulary test package (a pretest and a post-test) each containing 20 multiple-choice items on the new words and it took 20 minutes. To develop these tests, a table of specifications indicating the lexical considerations of the course (Interchange intermediate) was developed. Two parallel 20 -item multiple choice tests were made based on this table (one for pretest and one for post-test) (see appendix B \& C).

\subsection{Procedure}

To complete the course of study, four stages were followed: First the KET was piloted on 30 participants demonstrating almost similar characteristics as the target sample before the actual administration in order to make sure that the test had appropriate reliability (0.93) and item characteristics (no items were modified or removed) and thus suitable for the target sample. The administration of the whole test took 1 hour and 40 minutes.

The second stage consisted of administering the piloted KET to help the researcher make sure about the homogeneity of the participants regarding their language proficiency. Having administered the test used for homogenization, out of 90 students the eligible ones -those 60 whose scores ranged from one standard deviation above and below the mean on the test were selected to serve as the participants of the study. The participants were then randomly assigned to two homogeneous groups (30 participants in each group). Last but not least was the piloting and administration of the vocabulary tests. In order to pilot the vocabulary tests, they were administered to 30 students enrolled in intermediate courses in the institute at the beginning of the educational semester. As a result of item analysis (Item facility, discrimination, and choice distribution), 5 items were modified ( 2 in pretest and 3 in post-test) to make the key and the distracters more appropriate. After these steps, the reliability of the pretest was calculated to be 0.86 and that of the post-test was 0.81 as estimated by Spearman-Brown Prophecy formula.

In the fourth phase of the study, the two experimental groups were administered the researcher made vocabulary pretest at the beginning of the first educational semester, during a regularly scheduled class. Before the test was administered, participants were provided with an explanation of the study being conducted and were assured that the results would have no influence on the course outcomes. The pretest was conducted to assess the vocabulary knowledge of the two groups before the course of instruction and to check their homogeneity in vocabulary knowledge prior to the treatment. In the fifth phase, the intervention, the two groups were taught during a course of 15 sessions. Four chapters were covered during the course in which grammatical, lexical and functional skills were practiced. However, each one of the two groups received a different treatment with regard to the teaching of new lexical items.

In the first experimental group, learners experienced the well known way of learning the vocabulary (lexical translation), i.e. through the provision of Persian translation by the teacher. The students were introduced to bilingual English to Persian dictionaries and were taught how to use the dictionaries in looking up the Persian equivalents of the new words. Whenever a new vocabulary item came up the teacher provided the learners with the translation of the item. In other words the teacher explicitly taught all words until students had enough vocabulary knowledge to be able to understand the 
meaning of unknown words they came across. In this group after looking up the Persian equivalents to the new words, students were asked to read aloud and do their best to translate the dialogues and texts into Persian as acceptable as possible.

In the second experimental group, lexical inferencing instruction was introduced. The students were introduced to twelve contextual cues (Nassaji, 2004) to use while they were trying to infer the meaning of unknown lexical items. The first two sessions of the class involved an introduction to the twelve cues together with examples. In addition the students were encouraged to apply the cues to infer the meanings of some unknown words included in texts presented by the teacher. In the following sessions whenever a new word came up, students were given time to infer the meaning of the word by use of the cues they had learnt. These cues are classified into the following four levels (Bengelei, 2004; Junko, 2005; Nassaji 2004) and can be found in appendix A.

After coming up with the correct meaning of lexical items through contexts and the provision of the necessary feedback, the researcher invited the students to make new sentences with the taught lexis. The researcher gave feedback on the sentences made by the students. Then, the students were asked to make more sentences with the vocabulary as homework. This procedure was followed up to the end of the course.

In the final session of the two classrooms, the participants were administered the vocabulary post-test. This test was administered two weeks after the participants' final test since the researcher was dealing with retention and according to Haynie (1997), "two weeks were considered the least time lapse between the instruction and the test administration" (p.23). The test took about 20 minutes in which the participants answered 20 multiple choice questions on vocabulary items covered in the course.

\subsection{Design}

The design used in this study was quasi-experimental. A pre-test and a post-test were administered to collect the data. This type of research design shares many similarities with the traditional experimental design or randomized controlled trial, but specifically lacks the element of randomization. In the present study, since it was impossible for the researcher to change the place of students enrolled in different classes, students of the intermediate level (chosen through the administration of KET) enrolled in intact classes were selected to participate in the study, therefore the study used convenient sampling.

The two approaches towards teaching vocabulary (lexical translation and lexical inferencing) are the independent variables and the researcher attempted to find about their possible differential influence on vocabulary retention (dependent variable). In addition, language proficiency and gender were the control variables.

\subsection{Data Analysis}

Data analysis for this study was performed by employing Statistical Package for the Social Sciences (SPSS) Version 17.0. The current study involved mainly quantitative analysis including descriptive statistics and inferential ones. The statistical analyses conducted are as follow:

Descriptive statistics of the KET in piloting phase;

Descriptive statistics of the vocabulary pretest in the piloting phase;

Descriptive statistics of the vocabulary post-test in the piloting phase;

Reliability estimates of the KET, vocabulary pretest, and vocabulary post-test;

Descriptive statistics of KET main administration and the normality check;

Descriptive statistics of the vocabulary pretest and the normality check; 
An independent samples t-test of the vocabulary pretest scores to determine any significant difference between the participants in the two experimental groups prior to the treatment;

Descriptive statistics of the post-test and the normality check; and

An independent samples t-test of the post-test scores to determine any significant difference between the participants in the two experimental groups to investigate the first null hypothesis.

\section{Results and Discussion}

The present study was an attempt to investigate the comparative impact of the lexical translation and the lexical inferencing techniques on the vocabulary development of intermediate foreign language learners and to find an answer to the research question which stated:

Is there any significant difference between the effect of lexical translation and lexical inferencing techniques on EFL learners' vocabulary retention?

\subsection{Piloting the KET}

The first step in the analysis of the results was to pilot the Key English Test (KET). The KET consisted of 56 items including two sections of reading, writing (because of practical problems, listening and speaking parts of KET were not administered). The test had a total score of 56 and the administration of the test took 1 hour and 40 minutes. This test was administered to a group of 30 intermediate EFL learners at the same language institute bearing almost the same characteristics as the target sample. Table 1 presents the descriptive statistics of KET at the piloting stage.

Table 1

Descriptive Statistics of the KET Piloting

\begin{tabular}{llllll}
\hline & $\mathrm{N}$ & Minimum & Maximum & Mean & Std. Deviation \\
\hline Ketpilot & 30 & 21.00 & 53.00 & 40.0000 & 10.15738 \\
Valid N (listwise) & 30 & & & & \\
\hline
\end{tabular}

The reliability of the test was calculated using K-R 21 formula. After analyzing items the reliability came out to be 0.93 which was satisfactory. Table 2 shows the reliability of the test scores gained by the participants in the KET piloting phase.

Table 2

Reliability of the KET piloting

$\begin{array}{cc}\mathrm{K}-\mathrm{R} 21 \text { formula } & \text { N of Items } \\ .93 & 56\end{array}$

There were 21 writing items (Qs 36-56) with 25 marks in the test that were rated by two qualified teachers. The researcher used the Pearson correlation coefficient in order to calculate the inter-rater reliability between the raters. The results showed that there was a significant correlation between the two raters. Therefore, this gave assurance to the researcher that the same raters could be used for the actual administration of the test. The results are shown in table 3 .

Table 3

Inter-rater Reliability of the Two Raters in the Piloting for Writing Part (Correlations)

\begin{tabular}{lll}
\hline & Q 36-56 & Q 36-56 \\
\hline Q 36-56 Pearson Correlation & 1.000 & $.766^{* *}$ \\
Sig. (2-tailed) &. & .000 \\
N & 30 & 30 \\
Q 36-56 Pearson Correlation & $.766^{* *}$ & 1.000 \\
Sig. (2-tailed) & .000 &. \\
N & 30 & 30 \\
\hline$* *$ Correlation is significant at the 0.01 level. & &
\end{tabular}




\subsection{Piloting the vocabulary pretest and post-test}

As it was already stated, the pretest was administered in order to make sure that the participants were homogeneous in regards with their vocabulary knowledge. Moreover, all participants underwent a vocabulary post-test at the end of the instruction in order to measure how much of lexical items they have learned through lexical translation and lexical inferencing strategies. These two tests were researcher-made tests. To develop these tests, a table of specifications indicating the lexical considerations of the course (Interchange intermediate) was developed. Two parallel 20 -item multiple choice tests were made based on this table (one for pretest and one for post-test). In order to pilot these tests they were administrated to 30 randomly selected female students with almost the same characteristics as those in the target group in order to make sure that the tests had appropriate reliability and item characteristics and thus, were suitable for the target sample. The students had 20 minutes to answer the items. The correct answer to each item received one point and there was no penalty to wrong responses. The results are shown in table 4.

\section{Table 4}

Descriptive Statistics of the Vocabulary Tests Piloting

\begin{tabular}{llllll}
\hline & $\mathrm{N}$ & Minimum & Maximum & Mean & Std. Deviation \\
\hline Pretstnilot & 30 & 7.00 & 16.00 & 10.7667 & 2.02882 \\
posttstpilot & 30 & 7.00 & 15.00 & 11.4000 & 2.11073 \\
Valid N (listwise) & 30 & & & & \\
\hline
\end{tabular}

The reliability of each of the tests was calculated using K-R 21 formula. After the vocabulary test package was finalized (the key and distracters in five items were modified) the reliability came out to be 0.86 for the pretest and 0.81 for the post-test which were satisfactory. Table 5 shows the reliability of the test scores gained by the participants in the two tests' piloting phase.

Table 5

Reliability of the vocabulary tests piloting

\begin{tabular}{lll}
\hline & K-R 21 formula & N of items \\
\hline Pretstpilot & .86 & 20 \\
Posttstpilot & .81 & 20 \\
\hline
\end{tabular}

\subsection{Proficiency KET Main Administration}

The researcher used the piloted KET as instrument for homogenizing the subjects of the study. From among 90 students who took the test, the researcher selected 60 intermediate students whose scores fell between one standard deviation above and below the mean and randomly assigned them to two experimental groups- lexical translation and lexical inferencing. Just as was done in the piloting phase, descriptive statistics was conducted after the administration of the test. The descriptive statistics of the selected participants on the proficiency test $(n=60)$ are presented in table 6 .

Table 6

Descriptive Statistics of the KET Main Administration

\begin{tabular}{lrccccrr}
\hline & $\mathrm{N}$ & Minimum & Maximum & Mean & \multicolumn{2}{c}{ Std. Deviation } & \multicolumn{2}{c}{ Skewness } \\
\cline { 2 - 7 } & Statistic & Statistic & Statistic & Statistic & Statistic & Statistic & Std. Error \\
\hline Mainket $^{2}$ & 60 & 21.00 & 44.00 & 33.6000 & 6.56958 & -.225 & .309 \\
Valid N (listwise) & 60 & & & & & & \\
\hline
\end{tabular}

The selected 60 participants were randomly divided into two groups (inferencing and translation). The following table shows the descriptive statistics for the performance of the inferencing group in language proficiency test. 
Table 7

Descriptive Statistics of the KET Main Administration for the lexical inferencing group

\begin{tabular}{lrrrrrrr}
\hline & \multicolumn{1}{c}{$\mathrm{N}$} & Minimum & Maximum & Mean & Std. Deviation & \multicolumn{2}{c}{ Skewness } \\
\cline { 2 - 8 } & \multicolumn{1}{c}{ Statistic } & Statistic & Statistic & Statistic & Statistic & Statistic & Std. Error \\
\hline infencing & 30 & 21.00 & 43.00 & 34.7333 & 6.06251 & -.419 & .427 \\
Valid N (listwise) & 30 & & & & & & \\
\hline
\end{tabular}

Similarly the performance of the translation group can be seen in the following table:

Table 8

Descriptive Statistics of the KET Main Administration for the lexical translation group

\begin{tabular}{lrcccccr}
\hline & $\mathrm{N}$ & Minimum & Maximum & Mean & \multicolumn{2}{c}{ Std. Deviation } & \multicolumn{2}{c}{ Skewness } \\
\hline & Statistic & Statistic & Statistic & Statistic & Statistic & Statistic & Std. Error \\
\hline Translation & 30 & 21.00 & 44.00 & 32.4667 & 6.95668 & .004 & .427 \\
Valid N (listwise) & 30 & & & & & & \\
\hline
\end{tabular}

What was needed then was to first test the data to determine whether it was normally distributed. This means that the data is not full of anomalies that can create inaccurate results. The normality was checked through Skewness/standard error of skewness which is within plus/minus 1.96 in both groups, suggesting that the data was normally distributed.

\subsection{Vocabulary Pretest Main Administration}

Before starting the treatment, a vocabulary pre-test, was administered by the researcher in order to make sure that the participants in both groups had no prior knowledge of the target words. Just as was done in the KET administration, descriptive statistics was conducted after the administration of the test. Tables 9 shows the statistics for both lexical translation $(\mathrm{M}=10.66$ and $\mathrm{SD}=2.36)$ and lexical inferencing $(\mathrm{M}=10.80$ and $\mathrm{SD}=2.21)$ groups respectively.

Table 9

Descriptive Statistics of the Vocabulary Pre-tests' Scores

\begin{tabular}{lccccccc}
\hline & $\mathrm{N}$ & Minimum & Maximum & Mean & Std. Deviation & \multicolumn{2}{c}{ Skewness } \\
\hline & Statistic & Statistic & Statistic & Statistic & Statistic & Statistic & Std. Error \\
\hline Preinfrencing & 30 & 7.00 & 15.00 & 10.8000 & 2.21904 & .169 & .427 \\
Pretranslation & 30 & 6.00 & 16.00 & 10.6667 & 2.36837 & .094 & .427 \\
Valid N (listwise) & 30 & & & & & & \\
\hline
\end{tabular}

The normality is checked through Skewness/standard error of skewness which is within plus/minus 1.96 in both groups, suggesting that the data was normally distributed. An independent samples t-test was run to compare the performance of the two groups with respect to the vocabulary pretest main administration. The result from the administration of this test is presented in the table 10 below.

Table 10

Independent samples t test of the vocabulary Pre-tests Scores

\begin{tabular}{|c|c|c|c|c|c|c|c|c|c|c|}
\hline & & \multirow{2}{*}{\multicolumn{9}{|c|}{$\begin{array}{l}\text { Levene's Test for } \\
\text { Equality of Variances } t \text {-test for Equality of Means }\end{array}$}} \\
\hline & & & & & & & & & & \\
\hline & & \multirow[b]{2}{*}{$\mathrm{F}$} & \multirow[b]{2}{*}{ Sig. } & \multirow[b]{2}{*}{$\mathrm{t}$} & \multirow[b]{2}{*}{ Df } & \multirow[b]{2}{*}{$\begin{array}{l}\text { Sig. }(2- \\
\text { tailed) }\end{array}$} & \multirow[b]{2}{*}{$\begin{array}{c}\text { Mean } \\
\text { Difference }\end{array}$} & \multirow[b]{2}{*}{$\begin{array}{l}\text { Std. Error } \\
\text { Difference }\end{array}$} & \multicolumn{2}{|c|}{$95 \%$ Confidence Interval of the Difference } \\
\hline & & & & & & & & & Lower & Upper \\
\hline \multirow[t]{2}{*}{ Pretest } & $\begin{array}{l}\text { Equal variances } \\
\text { assumed }\end{array}$ & .056 & .814 & .225 & 58 & .823 & .13333 & .59255 & -1.05278 & 1.31944 \\
\hline & $\begin{array}{l}\text { Equal variances not } \\
\text { assumed }\end{array}$ & & & .225 & 57.756 & .823 & .13333 & .59255 & -1.05288 & 1.31955 \\
\hline
\end{tabular}


As it is seen in the table $(\mathrm{t}=.225, \mathrm{df}=58, \mathrm{p}=.823>.05)$, the observed $\mathrm{t}$ is not significant at 0.05 level of significance $(\mathrm{t}=.225)$ since the significance is 0.823 which is larger than the level of significance chosen $(\mathrm{p}<.05)$. In other words there was no significant difference between the two groups at the beginning of the instruction with regard to their knowledge of the selected vocabulary items.

\subsection{Vocabulary Post-test Main Administration}

The target words were taught to the participants in the first experimental group through the lexical inferencing strategy and in the second experimental group through the lexical translation strategy during the semester. After conducting the treatment sessions, the post-test was administered. The results of the main administration for both groups are shown in tables 11 and 12 respectively in the following section.

In order to investigate the possibility of a significant difference between the performances of the two groups, an independent samples t-test was applied to compare the mean scores of the two groups of students. Tables 11 below shows the mean and standard deviation of the groups on the vocabulary post-test. Results point to an improvement (around 5 points in the inferencing and 2 points in the translation group) in the post-test suggesting that the lexical inferencing group has outperformed the lexical translation group.

Table 11

Descriptive Statistics of the Experimental Groups' Vocabulary Post-test

\begin{tabular}{lccccccc}
\hline & $\mathrm{N}$ & Minimum & Maximum & Mean & Std. Deviation & \multicolumn{2}{c}{ Skewness } \\
\cline { 2 - 8 } & Statistic & Statistic & Statistic & Statistic & Statistic & Statistic & Std. Error \\
\hline Postinfrencing & 30 & 11.00 & 20.00 & 15.5333 & 2.09652 & -.146 & .427 \\
Posttranslation & 30 & 9.00 & 18.00 & 12.9333 & 2.66437 & .405 & .427 \\
Valid N (listwise) & 30 & & & & & & \\
\hline
\end{tabular}

What was needed was to test the data to determine if it is normally distributed. The normality is checked through Skewness/standard error of skewness which is within plus/minus 1.96 in both groups, suggesting that the data was normally distributed. In order to examine the comparative effect of lexical inferencing and lexical translation as teaching techniques in improving the ability of students in retaining newly faced lexical items, the scores on the vocabulary post-test of the lexical inferencing group, and the scores obtained from the lexical translation group vocabulary post-test were compared through applying an independent samples t-test. The results were to show whether or not there had been any significant difference in the performance of the two groups in the post-test of vocabulary. These results are shown in table 12 below.

Table 12

Independent Samples $t$-test on the Groups' Vocabulary Post-test

\begin{tabular}{|c|c|c|c|c|c|c|c|c|c|c|}
\hline & & \multicolumn{9}{|c|}{$\begin{array}{l}\text { Levene's Test for } \\
\text { Equality of Variances } t \text {-test for Equality of Means }\end{array}$} \\
\hline & & \multicolumn{9}{|c|}{$95 \%$ Confidence Interval of the Difference } \\
\hline & & $\mathrm{F}$ & Sig. & $\mathrm{t}$ & Df & $\begin{array}{l}\text { Sig. }(2- \\
\text { tailed) }\end{array}$ & $\begin{array}{c}\text { Mean } \\
\text { Difference }\end{array}$ & $\begin{array}{l}\text { Std. Error } \\
\text { Difference }\end{array}$ & Lower & Upper \\
\hline \multirow[t]{2}{*}{ posttest } & $\begin{array}{l}\text { Equal variances } \\
\text { assumed }\end{array}$ & 1.496 & .226 & 4.200 & 58 & .000 & 2.60000 & .61898 & 1.36097 & 3.83903 \\
\hline & $\begin{array}{l}\text { Equal variances } \\
\text { not assumed }\end{array}$ & & & 4.200 & 54.960 & .000 & 2.60000 & .61898 & 1.35951 & 3.84049 \\
\hline
\end{tabular}

As the table shows $(\mathrm{t}=4.2, \mathrm{df}=58, \mathrm{p}=.000)$, the observed mean difference is significant at $\mathrm{p}=.05$ level of significance $(\mathrm{t}=4.20)$. This amounts to saying that the two groups had significantly different 
performances on the post-test of vocabulary. Comparing the mean of the two groups makes it clear that the lexical inferencing group performed better than the lexical translation group.

\subsection{Discussion}

The null hypothesis of the study was rejected according to the results of the data analysis. The findings indicated that both of the lexical translation and lexical inferencing techniques helped the participants to learn and recall the target vocabulary items. However, the results of the vocabulary post-tests strongly indicated that learning the lexical items through the lexical inferencing technique was more effective and efficient. In other words, the participants who were exposed to lexical inferencing technique exhibited enhanced retention of the target vocabulary.

This result corroborates the findings of Cooper (1999). His study showed that successful learners use strategies to learn idioms. However, there seems to be some discrepancy between the findings of the present study as to the learner's ability to retain lexical items presented through the lexical inferencing technique and those of Prince (1996, p.478), who states, "Results reveal a superiority of translation learning in terms of quantity but an inability in the part of weaker learners to transfer their knowledge into L2 contexts." The observed inconsistency here might be due to a multitude of factors such as the differences in the measurement tools, proficiency level of the learners, operational definition of learning and retention, and motivational factors in driving the learners to try their best and so forth.

Theoretically, perhaps there is place to claim a stronger relationship between learning vocabulary through inferencing and higher levels of achievements than learning the words through memorizing their translation equivalents. One probable explanation is that inferencing techniques involving deeper mental processing are more sophisticated and require greater cognitive effort than those with shallow processing. However, they might be too difficult and time-consuming for younger learners to employ. Like Schmitt's (1997) argument, deeper processing involves the kind of elaborative mental processing and requires a greater cognitive effort; thus, more mature learners can realize their values.

In addition, the lexical inferencing technique can pave the way for the negotiation of meaning to occur in classroom. According to Long (1996) interaction hypothesis emphasizes the role of negotiation of meaning in facilitating language acquisition. Negotiation of meaning occurs when input is conversationally modified by second language learners in order to ensure that input is modified to exactly the level of comprehensibility they can manage, which is the key for comprehensible input as suggested by interaction hypothesis.

From a conceptual point of view, the claims on the positive impact of lexical inferencing on vocabulary development tie up with a view of language learning as an essentially social phenomenon (Bruner, 1978; Vygotsky, 1978; Wells, 1985). Following Vygotsky (1978), a distinction can be drawn between learners' actual developmental level and their potential developmental level. The actual developmental level defines the limits of what learners, at any moment in their development, can do and understand on their own through independent problem solving. Problems that learners cannot yet tackle on their own may act as a powerful incentive to overcome these limits, at least if the problems are dealt with. Experiencing how new problems may be solved, or actively collaborating with others in doing so, may guide learners toward independently solving similar problems in the future.

\section{Conclusion}

Using a quasi-experimental (a design in which the pretests are administered before the application of the treatment and posttests at the end of the treatment period), attempt was made to compare the effect of lexical inferencing and lexical translation techniques on Iranian female EFL learners' 
vocabulary development. Average performance between groups significantly differed on the posttest. That is, the inferencing group outperformed the translation group in their vocabulary achievement.

Reconfirming the results of some previous studies, the present study showed that using lexical inferencing techniques, teachers can help their students to improve their vocabulary knowledge. The present study provides English language teachers with information about lexical inferencing and the way to use it in different stages of teaching vocabulary. A lot of benefits can be attributed to the application of lexical inferening techniques in the language classroom which can be explained through currently favored theories of second language learning and teaching.

\subsection{Pedagogical Implications}

From the practical perspective, the findings of this study have implications for teachers and students. Teachers may enhance the vocabulary knowledge of their EFL students by acquainting them with the wisdom underlying the lexical inferencing technique. Teachers may use it to assist their students to achieve a sound knowledge of what they are supposed to learn. Therefore lexical inferencing is significant for both teachers and students in many ways.

Lexical inferencing can be used as an effective learning strategy for learning vocabulary, replacing the traditional methods of teaching lexicon, with the great advantage of student participation. It must be noted that the use of the lexical inferencing technique is not limited to language schools. In other words, it can be used as an effective teaching technique in ESP educational context in colleges and universities.

While trying to infer the meaning of new lexical items, students usually get involved with lively interactions with the instructor and their peers. In the Interaction Hypothesis, Michael Long (1981, 1983) proposes that while both input and output are necessary for second language acquisition, in order to gain a greater understanding of how this works, one should focus more attention on the interactions language learners engage in. Long posits that these interactions are not merely a source of second language input, but are rather exchanges that allow the parties to negotiate the meaning of the input. This negotiation results in changes to the complexity of the input.

According to Long (1981), these changes to the input play an important role in second language acquisition. For a second language learner, interaction allows for the fine-tuning of the second language input in order to make it more accessible to the learner. In studies when communication or comprehension difficulties arise in interaction between native and non-native speaker pairs, more often than not these pairs attempt to resolve their difficulties by using conversational tactics such as requesting repetition (i.e., "Could you repeat that, please?"), confirmation checks (i.e., "Did you say..."), comprehension checks (i.e., "Does x mean x?"), and/or clarification requests (i.e., "What do you mean by $\mathrm{x}$ ?"). Therefore, the modifications to the conversational structure ensure that the input will be comprehensible while still containing new material in the form of new vocabulary which provides the potential for new learning.

Moreover and according to the sociocultural theory (Lantolf, 2006) interaction need not be solely two-way in nature. In other words students are sometimes involved in self talk which helps them infer meaning and comprehend best. Ohta (2001) provides evidence on how her students in a Japanese EFL context use private speech during the task of learning English. Through the lexical inferencing technique, too, students are expected to get involved in a lot of self talk in their attempt to come up with the meaning of newly faced lexical items.

As the results of the study indicated, learners involved in lexical inferencing will have greater lexical resource. Therefore, teachers should make their best to raise their students' awareness of this potential and help them develop their skills as well as they can. Paying more attention to developing 
these techniques in students can help them become more interpretive. By consciously focusing on new lexical items, students become aware of its nature and only then can they do something about it. Closely monitoring how they infer meaning will enable them to know about the nature and the quality of vocabulary knowledge.

Due to the key role vocabulary plays in communication in general, and in reading comprehension in particular, students' attention should be directed to considering word knowledge more seriously than before. Therefore, teachers are recommended to hold some extra classes at the beginning of the school year to introduce students to the lexical inferencing technique in an attempt to provide more support for students to narrow the gap of not knowing sufficient number of words in English.

Finally, Text-book writers are suggested to consider the techniques of lexical inferencing to be introduced in parts of the book chapters. In other words, they are suggested to revise the texts paying much more attention to the techniques of acquiring new lexical items included in the texts if the rationale behind developing the text-book is to prepare students to take care of their academic needs. In addition and with increasing the number and type of exercises included in the book, text-book writers may consider developing exercises with a more emphasis on vocabulary learning techniques specially the lexical inferencing technique.

\subsection{Suggestions for Further Research}

The present study was limited to only one language school, one level of proficiency, 18-30 year-old female participants. The influence of the two techniques of lexical translation and lexical inferencing on learning outcomes in EFL context, in language skills such as reading comprehension needs further research. That is, whether employing lexical inferencing or translation during the learning process would result in higher grades in learners' reading comprehension ability. In addition, the limited scope of this study did not let the researcher to investigate the relationship between the proficiency level of students and the use of lexical translation and lexical inferencing techniques. Further research is required to test the possible relationship between the use of these techniques and proficiency level of students. Moreover a study can be designed to explore the differential effects of lexical translation and lexical inferencing techniques between the male and female language learners. Finally, another study can make use of a larger sample size to better investigate the performance of male and female students and even students with different majors on how they approach the task of learning new words.

\section{References}

Bogaards, P., \& Laufer, B. (Eds.). (2004).Vocabulary in a second language. Amsterdam: John Benjamins.

Bruner, J. (1978). The role of dialogue in language acquisition. The child's conception of language, 241-256.

Candlin, C. (1988). Methods in English language teaching. International English Language Teaching, Prentice Hall, New York.

Carter, R. (2001). Vocabulary. In R. Carter and D. Nunan (Eds.), The Cambridge guide to teaching English to speakers of other languages (pp. 42-47). Cambridge: Cambridge University Press.

Coady, J., \& Huckin, T. (Eds). (1997). Second language vocabulary acquisition. Cambridge: Cambridge University Press.

Cook, G. (2010). Translation in language teaching: An argument for reassessment: Oxford University Press.

Cooper, T. C. (1999). Processing of idioms by L2 learners of English. TESOL Quarterly, 33, 233262.

Folse, K. (2004). Vocabulary myths. Ann Arbor: University of Michigan.

Fowle, C. (2002). Vocabulary notebooks: Implementation and outcomes. ELT Journal, 56, 380-388. 
Haastrup, K. (1991). Lexical inferencing, procedures or talking about words: Receptive procedures in foreign language learning with special reference to English. Tubingen Germany: Gunter Narr.

İstifçi, İ. (2009). Lexical inferencing strategies of Turkish EFL learners. Journal of Language and Linguistic Studies, 5(1), 97-107.

Keyvanfar, A., \& Arya, N. (2009). The impact of context pregnancy on vocabulary retention of Iranian EFL learners. Journal of Teaching English as a Foreign Language Literature, 1(1), 31-48.

Knight, S. (1994). Dictionary use while reading: The effects on comprehension and vocabulary acquisition for students of different verbal abilities. The Modern Language Journal, 78, 285-299.

Lewis, M. (1993). The lexical approach. London: Language Teaching Publications.

Long, M. H. (1996). The Role of the linguistic environment in Second Language Acquisition, A Hand Book of Second language Acquisition. (W. C. Bhatia, Ed.) San Diego, CA: Academic Press.

Nation, P. (1990). Teaching and Learning vocabulary. New York: Newbury House.

Nation, P. (2001). Learning vocabulary in another language. Cambridge: Cambridge University Press.

Nattinger, J., \& DeCarrico, J. (1992). Lexical phrases and language teaching. Oxford: Oxford University Press.

Nunan, D. (1991). Language teaching methodology. UK: Prentice Hall.

Paribakht, T. S., \& Wesche, M. (1999). Reading and "incidental" L2 vocabulary acquisition: An introspective study of lexical inferencing. Studies in Second Language Acquisition, 21, 195-224.

Pellicer-Sanchez, A., \& Schmitt, N. (2010). Incidental vocabulary acquisition from an authentic novel: Do things fall apart. Reading in a Foreign Language, 1, 31-55.

Prince, P. (1996). Second language vocabulary learning: The role of context versus translation as a function of proficiency. The Modern Language Journal, 80, 478-493.

Richards, J. C. \& Rodgers, T. S. (2001). Approaches and methods in language teaching. Cambridge and New York: Cambridge University Press.

Schmitt, N. (2000). Vocabulary in language teaching. Cambridge: Cambridge University Press.

Schmitt, N., \& McCarthy, M. (1997). Vocabulary, description ,acquisition, and pedagogy. Cambridge: Cambridge University Press.

Shokouhi, H., \& Askari, H. (2010). The effect of guessing vocabulary in reading authentic texts among pre-university students.75 Arizona Working papers in SLA and teaching, 17, 75 -89.

Vasiljevic, Z. (2008).Teaching vocabulary to advanced Japanese students: A word association approach. The East Asian Learner, 44(2), 144-152.

Vygotsky, L. (1978). Interaction between learning and development. Readings on the development of children, 34-41.

Webb, S. (2008). The effects of context incidental vocabulary learning. Reading in a foreign Language, 2, 232-245.

Weigand, E. (1998). Contrastive lexical semantics. In E. Weigand (Ed.), Contrastive lexical semantics (pp. 25-44). Amsterdam: John Benjamin.

Wells, G. (1985). Language development in the pre-school years. Cambridge. Cambridge University Press.

Willis, J.D. (1990). The lexical syllabus. London: Collins COBUILD.

Zafarani, Z. (2009). Effects of different cognitive learning strategies on EFL learners' receptive retention of vocabulary. Journal of Teaching English as a Foreign Language and Literature, 1(1), 63-77.

Yali, G. (2010). L2 vocabulary acquisition through reading incidental learning and intentional learning Chinese. Journal of Applied Linguistics, 33(1), 74-93.

Zaid, M. A. (2009). A comparison of inferencing and meaning-guessing of new lexicon in context versus non-context vocabulary presentation. The Reading Matrix, 9(1), 56-66. 


\section{Appendix A}

\section{Levels Included in Lexical Inferring Instruction}

\begin{tabular}{|c|c|c|}
\hline Level & Categories & Sample sentences \\
\hline Word & $\begin{array}{l}\text { 1. Morphology } \\
\text { 2. Homonym } \\
\text { 3. Word association }\end{array}$ & $\begin{array}{l}\text { He likes outdoor activities. } \\
\text { I can't speak German or French. } \\
\text { Chocolate with powdered sugar is made into dark chocolate. }\end{array}$ \\
\hline Sentence & $\begin{array}{l}\text { 4. Sentence meaning } \\
\text { 5. Sentence grammar } \\
\text { 6. Punctuation rules }\end{array}$ & $\begin{array}{l}\text { There will be some booths in our annual fair like selling food, selling hand-made art. } \\
\text { It will give us time to decorate our house and prepare the food. } \\
\text { New year, a holiday for family reunion, has many customs. }\end{array}$ \\
\hline Discourse & $\begin{array}{l}\text { 7. Definition } \\
\text { 8.Comparison/contrast } \\
\text { 9. Cause and effect } \\
\text { 10. Discourse meaning } \\
\text { 11. Reflection of mood }\end{array}$ & $\begin{array}{l}\text { What is a hobby? It's something you do or make when you have free time. } \\
\text { Accidents happen every day. But they can be avoided if drivers are more careful. } \\
\text { Life here is terrific. I never taught that camping in Africa would be so fun. I am really } \\
\text { enjoying it. }\end{array}$ \\
\hline World knowledge & 12. World/background knowledge & number 3 platform is the train number 350 coming. Please stand in back of the red line. \\
\hline
\end{tabular}

Appendix (B):

PROFICIENCY TEST OF HOMOGENIZATION (KET)

Part 1

Which notice (A-H) says this?

1. Next week these will be more expensive.

2. You cannot eat this meal in the evening.

3. You may be late.

4. it's cheaper to buy three of these.

5. You must not leave this open.

A closed for lunch come back later

E Children under three eat free!

B All buses delayed

F Postcards 40p each or 3

C Fire door-keep closed at all times

G Country farm soup $100 \%$ fresh vegetables

D Special lunch until three 2:30 p.m. and 4:50

H Shoes half-price until Saturday

Part 2

Read the sentences about going to disco. Choose the best word (A, B or C) for each space.

6. Jane ......... Sarah outside the disco at 9:30.

A met B arrived C came

7. Jane was .............her new jeans.

A dressing B wearing $\quad$ p putting

8. There is a special .........for students on Thursdays.

A price $\quad B$ cost $\quad$ C money

9. They danced to some very ..........music.

A good B faster C nicest

10. Sarah ............Jane home in her car.

A went $\quad$ B look $\quad$ C travelled

Part 3

Complete the five conversations

11. Is lunch ready yet?

A Ten minutes ago.

B In a few more minutes.

C it's been too long. 
12. I' write a letter to you.

A Let me post it.

B That will be nice.

C It hasn't come yet.

13. Let's have a pizza.

A Not again.

B It doesn't matter.

C Not at all.

14. How does the washing machine work?

A Too much.

B Not often

C Like this.

15. I prefer swimming to tennis.
A I do too.
B I can't have it.
C That's better.

Complete the conversation between two friends.

What does Marie say to Gordon?

Gordon: I'm fine that's a lovely sweater you're wearing. Where did you buy it?

Marie: 16.

Gordon: it looks very expensive.

Marie: 17

Gordon: do you know where he bought it?

Marie: 18.

Gordon: is that the shop next to the pizza restaurant?

Marie: 19 .

Gordon: Do they sell sweaters for men?

Marie: 20 .

Gordon: Good. I must go and have a look.

A Yes. He always buys me nice things.

B The shopping centre has a lot of clothes shops

C No, I don't. He didn't tell me but he often buys things from New York.

D I'm fine, thanks, Gordon. How are you?

E I didn't. My brother gave it to me for my birthday.

F Oh, I'm sure they do. They have clothes for everyone.

G I don't have a lot of money for clothes.

$\mathrm{H}$ no, it's on the other side of the road.

Part 4

Read the article about Ingrid McFarlane and then answer the questions.

Ingrid McFarlane

Zoo Keeper

When I left school at eighteen, I got a job at a zoo as a student keeper. Now, five years later, things have changed- I have passed my exams and I am a full animal keeper. The money is not good. I only get $\$ 9.0000$ a year. You have to be outside in rain and snow, which is hard work, and you get very dirty. But this doesn't matter to me because animals are the most important thing in my life! There are a hundred monkeys and fifty deer in my part of the zoo and I give them their food and clean their houses. I also need to watch them carefully to be sure that they are all well. In fact, rhinos are my favorite animals and so last year I went top Africa with a colleague for a month to study them. The zoo is open every day and I work five different days each day. I live in a small flat twenty minutes away and I get up at ten to seven and start at eight. The first thing I do when I get home at quarter past five is have a shower!

21. Ingrid would like to
A take some exams.
B earn more money.
C change her job.

22. How does Ingrid feel about working in bad weather?

A she hates getting dirty.

B she doesn't mind it.

$\mathrm{C}$ she likes the snow.

23. If Ingrid doesn't check the monkeys,

A they may become ill

B they may get hungry.

C they may run away.

24. The animals Ingrid likes best are the

A monkeys

B deer

C rhinos

25. Ingrid travelled to Africa. 
26. The zoo is open

A only five days a week.

27. Ingrid arrives at her flat in the evening at

A five fifteen.

$\mathrm{C}$ ten to seven.

Part 5

Read the article about penguins.

Choose the best word (A, B, or C) for each space.

Penguins

There are seventeen different types of penguins. They can be (28) ........forty centimeters to more than one meter tall. They all (29) ....... in the south part of the world. In winter, they swim (30).........long ways to find warmer weather. In spring, (31).........penguins come together on the beaches of Antarctica. The female penguin has one or two eggs. She puts(32).........eggs on the ground and sits there to keep (33).........warm. But she doesn't sit all the time because penguins can move with one egg between their legs. (34)........the female penguin is sitting on the eggs, the male penguin brings her food. He also (35)..........this when the baby penguins are born.

$\begin{array}{lll}\text { 28. A FROM } & \text { B by } & \text { C between } \\ \text { 29. A lives } & \text { B live } & \text { C lived } \\ \text { 30. A one } & \text { B the } & \text { C a } \\ \text { 31.A lots } & \text { B much } & \text { C many } \\ \text { 32. A her } & \text { B hers } & \text { C she } \\ \text { 33. A it } & \text { B them } & \text { C their } \\ \text { 34. A When } & \text { B How } & \text { C Who } \\ \text { 35. A does } & \text { B do } & \text { C doing }\end{array}$

Part 6

Read the description of some things you can find in a school.

What is the word for each one?

36. Everyone has one of these to sit on.

C.

37. Sometimes this person gives you a lot of homework. T.........

38. This is the place where people have lessons.

39. In some schools, all the students have to wear this. U.

40. At school, you can look for information on this or write your homework on it. C...

Part 7

Complete these letters. Write ONE for each space.

Dear Mr. Chapman,

I have done my home work but I can't come (41)........class today. I (42)......broken my arm and the doctor says I must stay at home (43)........two days. Please send me some more work (44) I have nothing to do all day. Yours, Maria

Dear Maria,

I'm very sorry to hear (45)..........how (46)you break it?(47).... (46)..........you need them. is some home work for you. I (48) send you more books

Best wishes.

S. Chapman

Part 8

Read the information about a talk at a school. Complete Carla's notes.

Jim Jordan (Grey's Music Shop) will speak to class 7B about the music business Monday 10 March, 2:30p.m. School Hall

Carla, Jim Jordan can't come to talk next Monday, but Grey's WILL SEND John Jones and he will talk about the same thing. Can you meet him at the school entrance at $2 \mathrm{pm}$, half an hour before the talk starts? Bring him to the school office.

Thanks. S Becket

Carla's notes

Date: 10 March 
Read this postcard from your English pen -friend, Sam.

Here is a postcard of my town. Please send me a postcard from your town. What size is your town? What is the nicest part of your town? Where do you go in the evening?

Write Sam a postcard. Answer the questions. Write 25-35 words.

Appendix (C): VOCABULARY TESTS

VOCABULARY PRETEST

In the name of Allah

Test of vocabulary

Name:

Student number:

Choose the best option:

We really expected to have fun at the cinema but the movie was a great

a. blast

b. disappointment

c. coincidence

d. waste

I was walking down the street when, ., it started to rain.
a. luckily
b. recently
c. fortunately
d. unexpectedly

Before he was born, the doctors warned his parents that he might have learning difficulties. He's been them wrong ever since.
a. declining
b. surprising
c. proving
d. performing

There are still many experts about just how much influence a volcanic explosion can have on the weather.
a. striking
b. stable
c. skeptical
d. nagging

Put on a plate and arrange the tomato on top. .......... some lemon juice and grind some black pepper onto the salad.
a. Squeeze
b. Harness
c. Boil down
d. Execute

When something is , it is very old

a. ingredient

b. ancient

c. gooey

d. stunning

The museum was founded in 1986 to ........... Korea's rich Kimchi culture. .
a. highlight
b. fabricate
c. tickle
d. trigger

in my country we grow coffee, manufacture cars, and ......... lobsters. .
a. raise
b. build
c. farm
d. plant

One of those old elusive memories from the back of my brain returned to ..... me. A confusing memory of something that had never happened to me.

$\begin{array}{llll}\text { a.baffle } & \text { b. spike } & \text { c. dominate dazzle }\end{array}$

The gas might come out of from there. Firemen located the ........... and sealed it off.

$\begin{array}{llll}\text { a.debris } & \text { b. seal c. leak } & \text { d. deficit }\end{array}$

The Empire State Building was by an American architect. It is located in New York City.
a.designed
b. counseled
c. constructed
d. featured

The study has revealed some very f. facts about whales.

$\begin{array}{llll}\text { a.intriguing } & \text { b. malleable } & \text { c. enterprising } & \text { d. chronic }\end{array}$

I could never be a .......... because I can't make decisions quickly.

$\begin{array}{llll}\text { a. teacher } & \text { b. journalist } & \text { c. stockbroker } & \text { d. waiter }\end{array}$

The .......... type is careful and likes to follow routines and keep track of details.
a. conventional
b. social
c. artistic
d. realistic

The program was a success. In fact, the initial training helped to individual's confidence.
a. endanger
b. reduce
c. boost
d. assure

It is difficult to ..... the importance of developing good study habits.

$\begin{array}{llll}\text { a. exaggerate } & \text { b. implant } & \text { c. transplant } & \text { d. transform }\end{array}$

Some people find unemployment difficult to ..........
a. perform
b. entertain
c. cope with
d. intimidate

The interviewer is normally required to ask specific questions but is free to
a. threaten
b. measure
c. interrupt
d. probe

The peace and .......... of our city make me realize how fortunate we are. Our family can lead a happy life here.
a. quiet
b. hysteria
c. failure
d. fluctuation 
If you do not accept our strategy and do it your own way, you will suffer the
a. jealousy
b. consequences
c. coincidence
d. events

VOCABULARY POST-TEST

In the name of Allah

Test of vocabulary

Name:

Student number:

When you are in love, you might suddenly be interested in things you used to
a. avoid
b. admit
c. penetrate
d. announce

She is able to .......... and motivate other students to undertake tasks and she shows qualities of leadership.
a. inspire
b. dazzle
c harness
d. monitor

I think I could never be a because I can't make decesions quickly.

a. teacher

b. reporter

c. journalist

d. stockbroker

If you want to become teacher's favorite student, you have to try to be ............
a. moody
b. punctual
c. disorganized
d. strict

A lot of Sheep is

in New Zeland.
a. stored
b. grown
c. made up
d. raised

The exhibit includes displays of cooking and materials related to making pickles.

$\begin{array}{llll}\text { a. currency } & \text { b. culture } & \text { c. utensils } & \text { d. pieces }\end{array}$

If something is ........., it is thick and sticky.
a. ancient
b. gooey
c. stunning
d. complimentary

When the manager arrived everything was in order. Our team had done an excellent job. "Excellent" is an opposite for the word:

$\begin{array}{llll}\text { a. marvelous } & \text { b. wonderful } & \text { c. terrific } & \text { d. terrible }\end{array}$

These sunglasses are specially designed to ............ your eyes against the harmful sun rays.
a. store
b. protect
c. support
d. prevent

When only two years old, baby bears no longer ........... on their parents for food.
a. rely
b. attribute
c. access
d. attach

We need to increase awareness of dangerous diseases like AIDS.

$\begin{array}{llll}\text { a. public } & \text { b. recent } & \text { c. silent } & \text { d. possible }\end{array}$

She was able to buy whatever she liked because she had ........... a lot of money.
a. recycled
b. inherited
c. reduced
d. distracted

My father smokes a lot. I am a bit about his health.

a. unconfident

b. natural

c. serious

d. concerned

The strategy you have chosen could ........... more problems than it solves.
a. cause
b. destroy
c. stop
d. trap

I think I can be a good businessman because I can . money well.

$\begin{array}{llll}\text { a. work } & \text { b. enjoy } & \text { c. manage d. mind }\end{array}$

We can help decrease pollution by using public

$\begin{array}{llll}\text { a. communication } & \text { b. transportation } & \text { c. reflection } & \text { d. extinction }\end{array}$

Parents worry about the ........... effect that some films may have on children.

$\begin{array}{llll}\text { a. attractive } & \text { b. repetitive } & \text { c. destructive } & \text { d. positive }\end{array}$

We all like the new manager, however, he is a bit ............

$\begin{array}{llll}\text { a. reliable b. efficient } & \text { c. creative } & \text { d. bad-tempered }\end{array}$

"What .......... is used in the European Union at the moment?" "I thing the euro is used."

$\begin{array}{llll}\text { a. currency } & \text { b. credit } & \text { c. union } & \text { d. patent }\end{array}$

Rice is .......... in warmer parts of this country.

$\begin{array}{llll}\text { a. manufactured } & \text { b. destroyed } & \text { c. cultivated } & \text { d. exported }\end{array}$ 